\title{
Pengaruh Keadilan Sistem Perpajakan dan Pengawasan Pajak, terhadap Tax Evasion (Studi Kasus Wajib Pajak di Daerah Istimewa Yogyakarta)
}

\section{The Effect of The Justice System of Taxation and Tax Supervision on Tax Evasion (A Case Study of Tax Payers in The Special Region of Yogyakarta)}

\author{
Nur Anita Candra Putry'1, Heru Juliansyah² \\ 1 Universitas Sarjanawiyata Tamansiswa - Yogyakarta \\ 2Universitas Sarjanawiyata Tamansiswa - Yogyakarta \\ Email: herujulian223@gmail.com
}

\begin{abstract}
ABSTRAK
Penelitian ini bertujuan untuk mengetahui pengaruh keadilan sistem perpajakan, pengawasan pajak terhadap tax evasion. Penelitian ini bersifat data kualitatif. Populasi yang digunakan dalam penelitian ini adalah wajib pajak orang pribadi . Pengambilan sampel penelitian ini menggunakan metode snowball sampling dan diperoleh 88 responden. Jenis data yang digunakan adalah data primer yang diperoleh dari responden wajib pajak orang pribadi DIY. Penelitian ini menggunakan analisis regresi berganda. Hasil regresi penelitian menemukan keadilan sistem perpajakan terhadap tax evasion berpengaruh negatif dengan nilai signifikansi 0,013 dan nilai t 2,550 dan pengawasan pajak terhadap tax evasion tidak memiliki pengaruh dengan nilai signifikansi 0,741 dan nilai t $-0,331$.
\end{abstract}

Kata kunci: keadilan sistem perpajakan, pengawasan pajak, tax evasion

\begin{abstract}
This study aims to determine the effect of tax system fairness, tax control on tax evasion. This research is qualitative data. The population used in this study is an individual taxpayer. The sampling method used in this research was snowball sampling and obtained 88 respondents. The type of data used is primary data obtained from individual DIY taxpayer respondents. This study uses multiple regression analysis. The regression results of the study found that taxation system justice has a negative effect with a significance value of 0.013 and a $t$ value of 2.550 and tax control on tax evasion has no effect with a significance value of 0.741 and a value of $t-0.331$.
\end{abstract}

Key words: tax system justice, tax control, tax evasion 


\section{PENDAHULUAN}

Undang-Undang Republik Indonesia Nomor 16 Tahun 2009 Pasal 1 ayat 1 tentang Ketentuan Umum dan Tata Cara Perpajakan megartikan pajak sebagai kontribusi wajib kepada negara yang bersifat memaksa kepada badan/orang pribadi dengan tidak secara langsung medapatkan imbalan serta dapat digunakan untuk memenuhi keperluan rakyat Indonesia agar makmur. Fenomena yang terkait dengan penggelapan pajak yaitu PT. KJS Purwokerto. PT. KJS diduga dengan sengaja tidak menyampaikan keterangan yang tidak benar sehingga merugikan negara sebesar 5,1 miliar (finance.detik.com, 2020).

Dari uraian di atas yang terpapar di atas merupakan bukti bahwa tindakan tax evasion selama beberapa kurun waktu ini masih menjadi isu yang penting dan menarik untuk mendapatan perhatian yang lebih.Dalam hal ini tindakan tax evasion yang dilakukan oleh WP akan dianggap suatu perbuatan yang etis dikarenakan buruknya kondisi birokrasi yang ada dan sangat kecilnya kesadaran hukum terhadap tindakan tax evasion. Tax evasion lebih banyak dilakukan oleh wajib pajak dibandingkan dengan tindakan penghindaran pajak karena dalam melakukan penghindaran pajak diperlukan pengetahuan dan wawasan yang luas dalam mengetahui seluk beluk peraturan perundang-undangan tentang perpajakan dengan mencari celah peraturan pajak yang dapat digunakan untuk mengurangi beban pajak yang dibayarkan wajib pajak tanpa melanggar peraturan perpajakan yang berlaku (Utami \& Helmy, 2016)

Faktor yang mendorong wajib pajak dalam melakukan tindakan tax evasion keadilan sistem perpajakan, dan pengawasan perpajakan. Mardiasmo (2018) mengatakan bahwa untuk mencapai keadilan, undang-undang dalam pelaksanaan pemungutan pajak harus dilakukan secara adil sesuai dengan tujuan hukum. Adil dalam perundang-undangan dikenakan pajak secara umum dan merata, serta harus sesuai dengan kemampuan pendapatan yang didapat masing-masing wajib pajak. Sedangkan adil dalam pelaksanaannya dengan memberikan hak kepada semua wajib pajak untuk mengajukan penundaan dalam pembayaran, mengajukan keberatan dan mengajukan banding kepada Majelis Pertimbangan Pajak. Adanya keadilan dalam sistem perpajakan yang semakin baik akan mendorong perilaku wajib pajak untuk patuh akan kewajibannya yang berlaku, sehingga akan semakin rendah tindakan wajib pajak melakukan tindakan tax evasion (Mughal, 2012). Dengan demikian keadilan pajak terhadap tax evasion memiliki pengaruh negatif.

Hasil tersebut didukung oleh penelitian terdahulu telah dilakukan oleh Paramita \& Budiasih (2016) dan Wahyuni dan Sulindawati (2016) yang menyebutkan keadilan sistem perpajakan terhadap tax evasion berpengaruh negatif. Penelitian ini tidak didukung dengan hasil yang diteliti oleh Maghfiroh \& Fajarwati (2016) dan Indriyani et al., (2016) menyatakan keadilan sistem perpajakan terhadap pengggelapan pajak tidak memiliki pengaruh. Penelitian ini juga tidak sejalan dengan penelitian Sasmito (2017) dan Ervana (2019) yang menunjukkan hasil bahwa keadilan sistem pajak terhadap tax evasion berpengaruh positif.

Pengawasan pajak salah satu faktor yang juga dapat mempengaruhi tax evasion. Pengawasan pajak dilakukan guna mengetahui apakah wajib pajak sudah wajar dan betul dalam membayarkan kewajiban pajaknya. Oleh karena itu, dukungan data sangat diperlukan untuk menunjukkan keseriusan wajib pajak dalam membayarkan pajaknya (www.pajak.go.id). Semakin tinggi Direktorat Jenderal Pajak melakukan pengawasan pada wajib pajak, maka akan semakin rendah wajib pajak melakukan tindakan tax evasion karena adanya sanksi perpajakan yang 
nantinya akan memberatkan wajib pajak jika terbukti melakukan tax evasion. Dengan demikian pengawasan pajak terhadap tax evasion memiliki pengaruh negatif. Penelitian sebelumnya memberikan hasil yang sejalan telah dilakukan oleh Abidin (2016) yang menyebutkan pengawasan pajak terhadap tax evasion berpengaruh negatif. Penelitian ini berbeda dengan hasil yang diteliti oleh Putra (2019) menyatakan pengawasan pajak terhadap tax evasion memiliki pengaruh positif.

\section{LANDASAN TEORI}

\section{Theory Of Planned Behavior}

Teori ini dikembangkan dari Theory of Reasoned Action (TRA), yang dicetuskan oleh Fishbein dan Ajzen pada tahun 1975. Theory of Planned Behavior menyatakan bahwa selain sikap terhadap tingkah laku dan norma-norma subjektif, individu juga mempertimbangkan kontrol tingkah laku yang dipersepsikannya melalui kemampuan mereka untuk melakukan tindakan tersebut. Dalam teori ini, perilaku yang dilakukan oleh individu timbul karena adanya niat yang mendorong mereka untuk melakukan tindakan tersebut. Munculnya niat dalam berperilaku ditentukan oleh tiga faktor penentu, yaitu:

1. Behavioral belief

Keyakinan tentang kemungkinan hasil dan evaluasi dari perilaku tersebut.

2. Normative belief

Keyakinan tentang norma yang diharapkan dan motivasi untuk memenuhi harapan tersebut.

3. Control beliefs

Serta keyakinan tentang adanya faktor yang dapat mendukung atau 11 menghalangi perilaku dan kesadaran akan kekuatan faktor tersebut.

\section{Pengembangan Hipotesis}

\section{Pengaruh Keadilan Sistem Perpajakan Terhadap Tax Evasion}

Pemungutan besarnya pajak harus sebanding dengan kemampuan wajib pajak untuk membayar pajak dan sesuai dengan manfaat yang diterimanya, sehingga dapat dikatakan bersifat adil. Semakin adilnya penerapan sistem perpajakan yang berlaku maka akan mendorong wajib pajak untuk membayar dan memenuhi kewajiban perpajakannya. Hal ini dapat miningkatkan kepatuhan wajib pajak sehingga dapat mengurangi tindakan wajib pajak dalam melakukan tax evasion (Sasmito, 2017). Hal tersebut sesuai dengan penelitian sebelumnya yang telah dilakukan oleh Paramita \& Budiasih (2016) dan Wahyuni dan Sulindawati (2016) yang menunjukkan bahwa terdapat pengaruh negatif keadilan sistem perpajakan pada tax evasion.

\section{H1: Pengaruh negatif keadilan sistem perpajakan terhadap tax evasion}

\section{Pengaruh Pengawasan Pajak Terhadap Tax Evasion}

Fungsi Pengawasan sebagai salah satu tugas pokok Direktorat Jenderal Pajak pada dasarnya meliputi kegiatan memantau wajib pajak dalam membayar pajak. Adanya pengawasan pajak yang dilakukan Direktorat Jenderal Pajak akan mempengaruhi perilaku seseorang dalam membayar dan melaporkan kewajiban perpajakannya. Pengawasan pajak dilakukan agar semua masyarakat patuh membayar pajak, apabila tidak mematuhi aturan pajak yang berlaku maka akan dilakukan pemeriksaan pajak yang pada akhirnya akan dikenakan sanksi pajak yang memberatkan wajib pajak. Artinya hal tersebut menunjukkan bahwa semakin tinggi pengawasan pajak, maka akan semakin rendah tindakan tax evasion. Sejalan denganTheory of Planned 
Behavior, variabel pengawasan perpajakan akan mendorong wajib pajak untuk berperilaku patuh akan kewajiban perpajakan yang berlaku. Hal tersebut sesuai dengan penelitian sebelumnya yang telah dilakukan oleh Abidin (2016) yang menyebutkan pengawasan pajak terhadap tax evasionberpengaruh negatif. Penelitian ini berbeda dengan hasil yang diteliti oleh Putra (2019) menyatakan pengawasan pajak terhadap tax evasion memiliki pengaruh posistif.

\section{H2 : Pengawasan pajak terhadap tax evasion memiliki pengaruh negatif}

\section{METODOLOGI PENELITIAN}

\section{Jenis dan Sumber Data Penelitian}

Sifat penelitian yang digunakan merupakan bentuk penelitian kuantitatif. Penelitian ini menggunakan jenis data primer, sehingga penelitian dalam bentuk angka. Data tersebut diperoleh dari responden wajib pajak orang priadi DIY. Populasi dalam penelitian ini adalah seluruh wajib pajak orang pribadi. Adapun teknik pengambilan sampel dilakukan dengan snawball sampling. Sampel diperoleh 88 wajib pajak.

\section{Metode Analisis dan Hipotesisi Penelitian}

Pegujian penelitian ini menggunakan uji statistik deskriptive, uji kualitas data, uji asumsi klasik, uji analisis regresi linear berganda. Uji kualitas data pada penelitian ini yaitu uji validitas dan uji reabilitas. Uji asumsi klasik dalam penelitian ini terdiri dari uji normalitas, multikolinearitas, heteroskedastisitas. Pengujian hipotesis untuk mengetahui pengaruh variabel independen pada variabel dependen menggunakan model analisis regresi linear berganda.

\section{Operasional Variabel Penelitian}

Operasional variabel penelitian ini menggunakan variabel bebas yaitu keadilan sistem perpajakan, pengawasan pajak, serta variabel terikat pada penelitian ini yaitu tax evasion.

\section{Tax Evasion}

Penelitian ini dalam mengukur tax evasion diukur dengan skala linkert 5 point mulai dari sangat setuju, setuju, netral, tidak setuju, sangat tidak setuju.

Tabel 1

Pengukuran Variabel Tax Evasion

\begin{tabular}{|c|c|c|c|}
\hline Variabel & Definisi Operasional & Indikator & Skala \\
\hline Tax Evasion & $\begin{array}{l}\text { Penelitian ini menggunakan } \\
\text { satu variabel terikat yaitu tax } \\
\text { evasion. Tax evasion adalah } \\
\text { suatu tindakan penghindaran } \\
\text { pajak yang dilakukan oleh } \\
\text { wajib pajak dengan cara } \\
\text { melanggar undang-undang } \\
\text { perpajakan sehingga } \\
\text { pendapatan negara menurun } \\
\text { dan negara dapat dirugikan } \\
\text { (Abidin, 2016). }\end{array}$ & $\begin{array}{l}\text { 1. Peran kerja sama } \\
\text { yang baik antara fiskus } \\
\text { dan wajib pajak } \\
\text { 2. Pelaksanaan hukum } \\
\text { yang lemah } \\
\text { 3. Peluang penggelapan } \\
\text { pajak } \\
\text { 4. Integritas aparatur } \\
\text { perpajakan } \\
\text { 5. Sanksi tax evasion }\end{array}$ & Ordinal \\
\hline
\end{tabular}




\section{Keadilan Sistem Perpajakan}

Penelitian ini dalam mengukur keadilan sistem perpajakan diukur dengan skala linkert 5 point mulai dari sangat setuju, setuju, netral, tidak setuju, sangat tidak setuju.

Tabel 2

Pengukuran Variabel Keadilan Sistem Perpajakan

\begin{tabular}{|c|c|c|c|}
\hline Variabel & Definisi Operasional & Indikator & Skala \\
\hline \multirow{6}{*}{$\begin{array}{l}\text { Keadialan } \\
\text { Sistem } \\
\text { Perpajakan }\end{array}$} & Keadilan & 1. Keadilan & Ordinal \\
\hline & perpajakan adalah suatu & pemungutan pajak & \\
\hline & $\begin{array}{l}\text { keadilan yang diterapkan } \\
\text { dalam sistem pernaiakan }\end{array}$ & 2. Keadilan dalam & \\
\hline & $\begin{array}{l}\text { dalam sistem perpajakan } \\
\text { yang berlaku di Indonesia } \\
\text { (Sasmito, 2017). }\end{array}$ & $\begin{array}{l}\text { 3. Keadilan dalam ketentuan } \\
\text { perpajakak }\end{array}$ & \\
\hline & & $\begin{array}{l}\text { 4. Manfaat pajak yang di } \\
\text { setor }\end{array}$ & \\
\hline & & $\begin{array}{l}\text { 5. Kemampuan WP dalam } \\
\text { membayar pajak. }\end{array}$ & \\
\hline
\end{tabular}

\section{Pengawasan Pajak}

Penelitian ini dalam mengukur pengawasan pajak diukur dengan skala linkert 5 point mulai dari sangat setuju, setuju, netral, tidak setuju, sangat tidak setuju.

Tabel 3

Pengukuran Variabel Pengawasan Pajak

\begin{tabular}{|c|c|c|c|}
\hline Variabel & Definisi Operasional & Indikator & Skala \\
\hline $\begin{array}{l}\text { Pengawasan } \\
\text { Pajak }\end{array}$ & $\begin{array}{l}\text { Pengawasan pajak } \\
\text { adalah tindakan yang } \\
\text { dilakukan oleh DJP } \\
\text { untuk memeriksa dan } \\
\text { mengawasi WP dalam } \\
\text { membayar pajak } \\
\text { (Abidin, 2016). }\end{array}$ & $\begin{array}{l}\text { 1. Pemeriksaan dan } \\
\text { penpenyidikan } \\
\text { 2. Surat tagihan pajak } \\
\text { 3. Surat pemberitahuan } \\
\text { kepada WP } \\
\text { 4. Motivasi oleh pegawai } \\
\text { pajak } \\
\text { 5. Sanksi pajak }\end{array}$ & Ordinal \\
\hline
\end{tabular}

\section{HASIL DAN PEMBAHASAN}

\section{Hasil Penelitian}

Pengujian pada penelitian ini yang pertama yaitu menganalisi statistik deskriptif yang menampilkan data dalam bentuk tabel yang melingkupi informasi nilai minimum, maksimum, mean, dan standar deviasi. Pengujian kedua dilakukan uji kualitas data yaitu uji validitas dan reabilitas. Analisis yang ketiga menguji apakah hipotesis yang telah diajukan telah memenuhi 3 uji asumsi klasik yang diterapkan pada model regresi (Ghozali, 2018). Pengujian pada hipotesis penelitian ini menggunakan analisis regresi linear sederhana. Sebelum dilakukan penelitian yang sebenarnya, peneliti akan melakukan pilot test terlebih dahulu untuk mengevaluasi pernyataan dalam kuesioner. Hal ini dilakukan dengan cara mengambil sampel kecil (30 responden) untuk dilakukan pengujian validittas dan realibitas digunakan untuk menguji keandalan dan keakuratan suatu kuesioner yang telah dibuat. Hasil pilot test menunjukkan bahwa data kuesioner dinyatakan valid karena nilai sig dibawah dari 0,05 dan dinyatakan realibel karena nilai cronbach,s alpha lebih tinggi dari 0,600. 
Dapat ditunjukkan dari hasil uji kualitas data menunjukkan bahwa pada penelitian ini dinyatakan lulus uji validitas dan reabilitas. Tabel dibawah menunjukkan nilai $\mathrm{R}^{2}$ sebesar 0,109 yang memberikan penjelasan bahwa keadilan pajak dan pengawasan pajak terhadap tax evasion memiliki pengaruh sebesar $10,9 \%$ sisanya $89,1 \%$ dapat digambarkan oleh variabel bebas lainnya. Hasil uji output SPSS dapat dibuktikan dalam tabel sebagai berikut:

Tabel 4. Hasil Uji Hipotesis Penelitian

Analisis Regresi Linear Berganda

\begin{tabular}{|c|c|c|c|c|c|c|}
\hline \multirow{2}{*}{\multicolumn{2}{|c|}{ Model }} & \multicolumn{2}{|c|}{$\begin{array}{c}\text { Unstandardized } \\
\text { Coefficients }\end{array}$} & \multirow{2}{*}{$\begin{array}{c}\text { Standardized } \\
\text { Coefficients } \\
\text { Beta }\end{array}$} & \multirow[b]{2}{*}{$T$} & \multirow[b]{2}{*}{ Sig. } \\
\hline & & $B$ & Std. Error & & & \\
\hline 1 & (Constant) & 8,534 & 2,737 & & 3,118 &, 002 \\
\hline & Keadilan Pajak &, 515 & ,202 & ,397 & 2,550 &, 013 \\
\hline & Pengawasan Pajak &,- 062 & , 188 &,- 052 &,- 331 & ,741 \\
\hline & R Square & & & & & , 129 \\
\hline & Adjusted R Square & & & & & 109 \\
\hline & F hitung & & & & & 6,302 \\
\hline & Signifikansi & & & & & ,003 \\
\hline
\end{tabular}

Hasil uji $\mathrm{F}$ dalam penelitian ini menunjukkan hasil F-hitung 6,302 dan nilai signifikan sebesar 0,003 Hal ini memberikan kesimpulan bahwa nilai sig jauh diatas 0,05 maka hipotesis diterima, artinya salah satu variabel independen dapat berpengaruh. Berdasarkan tabel 1 dapat dilihat bahwa variabel keadilan pajak terhadap tax evasion memiliki pengaruh positif pada tingkat signifikansi $5 \%$. Keadilan pajak memiliki nilai signifikan sebesar 0,013>0,05 dengan nilai t statistik sebesar 2,550 dan nilai B sebesar 0,397. Dengan demikian, dapat disimpulkan bahwa adanya pengaruh positif hubungan keadilan pajak terhadap tax evasion, sehingga hipotesis yang menyatakan keadilan pajak berpengaruh negatif terhadap tax evasion tidak terdukung. Variabel keadilan pajak terhadap tax evasion memiliki pengaruh positif Hasil tersebut didukung dengan penelitian terdahulu yang telah dilakukan oleh Sasmito (2017) dan Ervana (2019) menyatakan bahwa adanya pengaruh positif antara keadilan sistem perpajakan pada penggelapan pajak. Penelitian berbeda dilakukan oleh Paramita \& Budiasih (2016) dan Wahyuni dan Sulindawati (2016) yang menyebutkan keadilan sistem perpajakan terhadap tax evasion berpengaruh negatif.

Hasil pengujian hipotesis kedua pada tabel 1 menunjukkan bahwa tidak adanya pengaruh pengawasan pajak terhadap tax evasion. Hal tersebut ditujukkan pada nilai t sebesar $-0,331$ dan nilai $B$ sebesar $-0,062$ dengan probabilitas signifikansi 0,741 jauh di atas 0,05 , maka hipotesis yang menyatakan bahwa pengawasan pajak terhadap tax evasion memiliki pengaruh negatif ditolak.

\section{REKOMENDASI KEBIJAKAN}

\section{Rekomendasi}

Berdasarkan hasil penelitian yang telah dilakukan pengujian data menggunakan SPSS V.20 sesuai dengan tujuan penelitian ini, maka adapun rekomendasi hasil dari penelitian ini sebagai berikut:

1. Hal ini menunjukkan bahwa keadilan sistem perpajakan berpengaruh positif dalam melakukan tax evasion. Hasil tersebut variabel keadilan sistem perpajakan dalam membayar 
pajak akan mempengaruhi perilaku wajib pajak. Apabila wajib pajak memperoleh ketidakadilan pada sistem perpajakan maka akan memicu timbulnya ketidakpatuhan wajib pajak dalam pembayaran pajak sehingga akan cenderung melakukan tax evasion. Ketika tingginya tingkat ketidakadilan sistem perpajakan, maka tindakan tax evasion akan semakin tinggi (Sasmito, 2017)

2. Hal ini menunjukkan bahwa pengawasan pajak tidak memiliki pengaruh dalam mempengaruhi perilaku wajib pajak untuk melakukan tax evasion. Hasil tersebut menunjukkan tinggi rendahnya pengawasan pajak tidak mengindikasikan wajib pajak telah melakukan penggelapan pajak. Ketika pengawasan pajak semakin tinggi, maka tidak mungkin terpantau wajib pajak yang melakukan penggelapan pajak sebelum dilakukan pemeriksaan mendalam dan pengadilan pajak karena banyaknya wajib pajak.

\section{Kebijakan}

Penelitian ini menguji pengaruh keadilan pajak dan pengawasan pajak terhadap tax evasion. Berdasarkan hasil penelitan ini dan interpretasi penelitian ini, maka peneliti dapat ditarik beberapa saran sebagai rekomendasi kebijakan antara lain :

1. Peneliti selanjutnya dapat menambah variabel lain yang dapat mempengaruhi tax evasion.

2. Peneliti selanjutnya diharapkan dapat menambah sampel penelitian yang lebih banyak lagi dengan ruang lingkup yang lebih luas lagi.

3. Peneliti selajutnya dapat melakukan pengumpulan sumber data atau sampel dengan melalkukan wawancara kepada responden, tidak hanya menggunkan kuesioner.

\section{DAFTAR PUSTAKA}

Abidin, N. (2016). Pengaruh Tarif Pajak, Sistem Perpajakan, Pengawasan Pajak Dan Sunset Policy Terhadap Minimalisasi Tax Evasion (Penggelapan Pajak). Revista Brasileira de Ergonomia, $9(2)$,

10. https://www.infodesign.org.br/infodesign/article/view/355\%0Ahttp://www.abergo.org.br/revist a/index.php/ae/article/view/731\%0Ahttp://www.abergo.org.br/revista/index.php/ae/article/vie w/269\%0Ahttp://www.abergo.org.br/revista/index.php/ae/article/view/106

Ervana, O. N. (2019). Pengaruh Pemeriksaan Pajak, Keadilan Pajak Dan Tarif Pajak Terhadap Etika Penggelapan Pajak (Studi Kasus Pada Kantor Pelayanan Pajak Pratama Klaten). Akuntansi Pajak, 1(1), 80-92. https://doi.org/10.24964/japd.v1i1.802

finance.detik.com. (2019). Mengenal soal Penghindaran Pajak yang Dituduhkan ke Adaro. In https://finance.detik.com/berita-ekonomi-bisnis/d-4612708/mengenal-soal-penghindaranpajak-yang-dituduhkan-ke-adaro.

Ghozali, I. (2018). Aplikasi Analisis Multivariate Dengan Program IBM SPSS 25 Edisi 9. Badan Penerbit Universitas Diponegorro.

Indriyani, M., Nurlaela, S., \& Wahyuningsih, E. M. (2016). Pengaruh Keadilan, Sistem Perpajakan, Diskriminasi dan Kemungkinan Terdeteksinya Kecurangan Terhadap Persepsi Wajib Pajak Orang Pribadi Mengenai Perilaku Tax Evasion. Prosiding Seminar Nasional IENACO, 818-825. 
Maghfiroh, D., \& Fajarwati, D. (2016). Persepsi Wajib Pajak Mengenai Pengaruh Keadilan, Sistem Perpajakan dan Sanksi Perpajakan Terhadap Penggelapan Pajak (Survey terhadap UMKM di Bekasi). Jrak, 7(1), 39-55.

Mardiasmo. (2018). Perpajakan Edisi Terbaru 2018.

Mughal, M. M. (2012). Reasons of Tax Avoidance and Tax Evasion: Reflections from Pakistan. Journal of Economics and Behavioral Studies, 4(4), 217-222. https://doi.org/10.22610/jebs.v4i4.320

Paramita, M., \& Budiasih, I. (2016). Pengaruh Sistem Perpajakan, Keadilan, Dan Teknologi Perpajakan Pada Persepsi Wajib Pajak Mengenai Penggelapan Pajak. E-Jurnal Akuntansi, 17(2), 1030-1056.

Putra, A. (2019). Pengaruh Sosialisasi Dan Pengawasan Terhadap Kepatuhan Wajib Pajak Pada Umkm Dengan Kesadaran Wajib Pajak Sebagai Variabel Intervening. Kemampuan Koneksi Matematis (Tinjauan Terhadap Pendekatan Pembelajaran Savi), 53(9), 1689-1699.

Sasmito, G. G. (2017). Pengaruh Tarif Pajak, Keadilan Sistem Perpajakan, Teknologi dan Informasi Perpajakan Terhadap Penggelapan Pajak. Artikel IImiah STIE Perbanas Surabaya, 1-17.

Undang-Undang Republik Indonesia Nomor 16 Tahun 2009. (n.d.). Undang-Undang Republik Indonesia Nomor 16 Tahun 2009 Tentang Ketentuan Umum Dan Tata Cara Perpajakan, 31 Desember 2008, Lembaran Negara Republik Indonesia Tahun 2008 Nomor 211. UndangUndang Republik Indonesia Nomor 16 Tahun 2009 Tentang Ketentuan Umum Dan Tata Cara Perpajakan, 31 Desember 2008, Lembaran Negara Republik Indonesia Tahun 2008 Nomor 211.

Utami, P. D. (2016). Pengaruh Tarif Pajak, Teknologi Dan Informasi Perpajakan, Dan Keadilan Sistem Perpajakan Terhadap Penggelapan Pajak (Studi Empiris WPOP yang Melakukan Kegiatan Usaha Di Kota Padang). Jurnal Akuntansi, 4(1), 893-904. http://ejournal.unp.ac.id/students/index.php/akt/article/view/2350/1859

Utami, P. D., \& Helmy, H. (2016). Pengaruh Tarif Pajak, Teknologi Informasi Perpajakan, dan Keadilan Sistem Terhadap Penggelapan Pajak: Studi Empiris pada WPOP yang Melakukan Usaha di Kota Padang. Wahana Riset Akuntansi, 4(2), 893-904.

Wahyuni dan Sulindawati. (2016). Pengaruh Keadilan, Sistem Perpajakan, Diskriminasi, Dan Biaya Kepatuhan Terhadap Persepsi Wajib Pajak Mengenai Etika Penggelapan Pajak (Tax Evasion) Pada Kpp Pratama Singaraja. JIMAT (Jurnal IImiah Mahasiswa Akuntansi S1), 6(3), 1-11. 